\title{
Medical and Social Circumstances of Lung Cancer Treatment in Italy or Europe
}

\author{
Erino A. Rendina \\ Division of Thoracic Surgery, Sapienza University of Rome
}

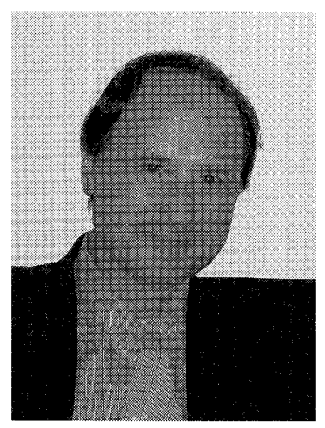

\begin{abstract}
Current Position: Professer and Chief of Thoracic Surgery, Sapienza University of Rome Head, Division of Thoracic Surgery, Sant'Andrea Hospital, Rome

Current Vice President (President 2008-2009): European Association for Cardio-Thoracic Surgery

Associate Editor: European Journal of Cardio-Thoracic Surgery
\end{abstract}

Lung cancer is the most common cause of death from neoplastic disease in Europe with an extimated number of 334.800 deceases (19.7\% of total) in 2006. It has been also the most frequent non-skin tumor until 2004 accounting for $13.3 \%$ of all cases, but this incidence is actually decreasing in the european area, with an extimated $12.1 \%$ rate of total ( 386.300 new cases) in 2006 . This incidence reduction has been registered together with the continous increasing of early diagnosed cases of breast cancer and colo-rectal cancer which have now become the two most common form of tumor in Europe. Furthermore, the more effective tabacco control, which has become an absolute priority in many countries of the european union, may have influenced this epidemiologic data. Direct effect of the improved smoking control, in the last years, has reduced death rates from lung cancer in men in most of the european countries with few exceptions (Portugal, Greece, Spain, France). However, lung cancer still remains largely the most common cause of death in the male sex, with 171.900 deaths extimated in 2006 (26.3\% of all cancer deaths) in the european population. Although less common than in men, it is the third cause death from tumor in women $(64.100,12.5 \%$ of total deaths in 2006) with high rates in Northen and Central Europe (first cause of death in Denmark, Sweden, Netherlands, Poland and United Kingdom in 2006) where the smoking rates remain high or are increasing.

The incidence of the histological subtypes of lung cancer has changed during the $20^{\text {th }}$ century in Europe. In particular, the proportion of adenocarcinoma has been increasing over time.

The number of patients with localized non small cell lung cancer who have received surgery in the last decade has been significantly higher than in the 1970s and 1980s. However the rate of patients that present inoperable disease at the moment of diagnosis is still high, up to $80 \%$ in several european countries. In 2006, it has been extimated that only $26 \%$ of patients aged under 70 and $14 \%$ of patients over 70 , diagnosed with lung cancer, have received surgical treatment in Europe. Among patients with non localized non small cell lung cancer and with small cell lung cancer there was a trend towards more chemotherapy. However, despite improvement in both the diagnosis and treatment, the overall prognosis for patients with NSCLC hardly improved over time. In contrast, the improvement of chemotherapic and radiotherapic regimens has produced increased survival rates for patients with small cell lung cancer in the last two decades. Anyhow, the overall 5 -year survival rate for patients with lung cancer in Europe does not exceed $15 \%$.

Surgery still represents the mainstay of treatment for lung cancer. The principal Institutions for lung cancer care all over Europe are therefore structured with the central role of the General Thoracic Surgery Units. The European Association for Cardio-Thoracic Surgery (EACTS) and the European Society of Thoracic Surgeons (ESTS) have defined the standard requirements and organization for the Units of General Thoracic Surgery in Europe, identifying two types of surgical units: the so called Units of Higher Specialization and the 
Units of Standard Care. The two types of Units are differentiated on the basis of the experience, workload and resources available, although both types of units should provide a dedicated team of surgeons, nurses and personnel. The Units of high specialization should be within a University setting or alternatively linked to a university. They should be headed by a surgeon certified by the European Board of Thoracic and Cardiovascular Surgery (EBTCS) or an equivalent body recognized by the EBTCS, preferably possessing academic qualifications. This head of the Department should be entrusted with educational and scientific responsabilities. These Units should perform more than $300 \pm 50$ major thoracic procedures per year and should preferably have access to a dedicated Intensive Care Unit and to more advanced imaging technique including MRI and, ideally, PET scanning.

The Units of Standard Care should be either freestanding or within a combined Unit with cardiac or general surgery but with personnel and resources clearly separated. The head of these units should be an EBTCScertified surgeon with a predominant and profiled engagement in General Thoracic Surgery. The overall number of major thoracic operations per year in such centres should be more than $150 \pm 50$. Minimum facilities should include:

-haematological, biochemical and microbiological laboratories

-endoscopic examinations

-radiological investigations including x-ray, ultrasound, contrast studies and CT scan

-cytology, histopathology and frozen section analysis.

Current facilities and arrangements for the treatment of lung cancer are of variable quality throughout Europe with resources being sometimes below an accettable level.

In Italy there are actually 50 officially recognized units of General Thoracic Surgery. Among these, 15 units are classified as Units of High Specialization. Seven of these are within a University centre or linked to a university, three are in National Cancer Institutes, three are in Research Institutes and two are in hospitals dedicated to oncologic and/or pulmonary diseases.

Being overall results of lung cancer treatment still disappointing, we have observed, also in several european countries, an increasing interest in screening programs in order to detect a larger number of localized and potentially curable tumors with the aim to improve long-term survival. Recent randomized and nonrandomized studies, including Italian experiences, evaluating the role of $\mathrm{CT}$ scan in lung cancer screening, have shown that the likelihood of individuals screened to be diagnosed with lung cancer is increased more than 3 -fold and the likelihood to undergo surgery is increased 10-folds if compared with the frequency expected in the absence of screening. However, these screening programs have produced neither a meaningful reduction in the number of advanced cancers diagnosed nor a reduction in the cancer-related deaths rate. Because of the paucity of evidence supporting lung cancer screening, several trials are being conducted in Europe with the aim to explore alternative approches to lung cancer prevention and early detection.

\section{REFERENCES}

1. Ferlay J, Autier P, Boniol M, Heanue M, Colombet M, Boyle. Estimates of cancer incidence and mortality in Europe in 2006. Ann Oncol 2007; 18: 581-92

2. Boyle P, Ferlay J. Cancer incidence and mortality in Europe, 2004. Ann Oncol 2005; 16: 481-88

3. Klepetko W, Aberg THJ, Lerut AE. Structure of General Thoracic Surgery in Europe. Eur J Cardiothorac Surg 2001; 20: $663-668$

4. Bach PB, Jett JR, Pastorino U, Tockman MS, Swensen SJ, Begg CB. Computed Tomography Screening and lung cancer outcomes. JAMA 2007; 297: 953-61 